\title{
Retraction Note to: Parameter estimation based on rainfall water characteristics and garlic nutrition human gastrointestinal absorption calculation
}

\author{
Yu Li ${ }^{1} \cdot$ Yingying Fan ${ }^{1}$
}

Published online: 9 November 2021

(c) Saudi Society for Geosciences 2021

Retraction Note to: Arabian Journal of Geosciences (2021) 14: 1586

https://doi.org/10.1007/s12517-021-07942-2

The Editor-in-Chief and the Publisher have retracted this article because the content of this article is nonsensical. The peer review process was not carried out in accordance with the Publisher's peer review policy. Author Yu Li has not responded to correspondence regarding this retraction. The Publisher has not been able to obtain a current email address for author Yingying Fan.

The original article can be found online at https://doi.org/10.1007/ s12517-021-07942-2.

Yu Li

liyuliyu76@163.com

1 College of Food Science and Technology, Henan Agricultural University, Zhengzhou 450002, Henan, China 